\title{
Spatial Plan Research based on a new generation of suburban logistics industry in China
}

\author{
Chengxin YAO*, ( Anhui Rural Revitalization Research Institute) School of architecture and planning, \\ Anhui Jianzhu University, China \\ Xueran QIN*, Anhui Shangyuan GuiHua Consulting Co.,Itd. China \\ Guangzhi ZUO, (Anhui Rural Revitalization Research Institute) School of architecture and planning, \\ Anhui Jianzhu University, China
}

\begin{abstract}
Under the background of the new Internet economy, the service objects and organizational models of the logistics network that are undergoing significant changes, the new logistics has become an important link connecting the real economy and the virtual economy. Making full use of the suburban space to develop a new generation of logistics industry carriers is an important means for cities to build core competitiveness and promote high-quality development. Consequently, this paper takes the representative logistics industrial park into suburbs of ChinaBaisi Logistics Group as an example to study and explore the spatial planning form and new development direction of the logistics industrial parks in the suburbs of Chinese cities in the new era. This paper puts forward the planning and construction mode of combining the change of spatial organization and investment subject, the combination of business form composition and Internet economic demand, the combination of supporting facilities and integrated development of industry and city, and the combination of landscape image shaping and 'Chinese dream', in order to seek a new breakthrough point and new growth pole to further promote the integrated development of urban and rural areas.
\end{abstract}

\section{Keywords}

Logistics Industrial Park, Internet Economy, Urban-Rural Integration, 'Chinese Dream'

\section{Introduction}

As the artery system of China's national economy, the logistics industry has maintained a positive trend of steady development. From 2011 to 2020, China's total social logistics increased from 158.4 trillion yuan to 300.1 trillion yuan (Figure 1). China still maintains the position of the world's largest and most dynamic logistics market. China's express business volume increased from 3.67 billion pieces to 83.36 billion pieces, more than 22 times the original in 10 years (Figure 2). With the rapid increase in the number of express delivery, the types of express delivery are also changing. As China's economy shifts from a stage of rapid growth to a stage of high-quality development, the development of the logistics industry has gradually matured, and the logistics operation system has become more complete. Consumption upgrades, industrial transformation and technological innovation have promoted new changes in the logistics industry. When new logistics has become an important link connecting real economy and virtual economy, making full use of urban suburban space to develop a new generation of 
logistics industrial park is an important means for cities to build core competitiveness and promote highquality development.

In recent years, there have been endless researches on China's logistics industry, and the representative ones are the views of Yude $\mathrm{He}$ and $\mathrm{Na} \mathrm{Li}$. Yude he (2016) selected the data of Sichuan Province in China from 2003 to 2013 and empirically studied the five logistics industry pillars. The results show that the development state of regional logistics system and economic system is constantly changing, and the coordinated development of the whole system is realized by giving play to the interaction mechanism.

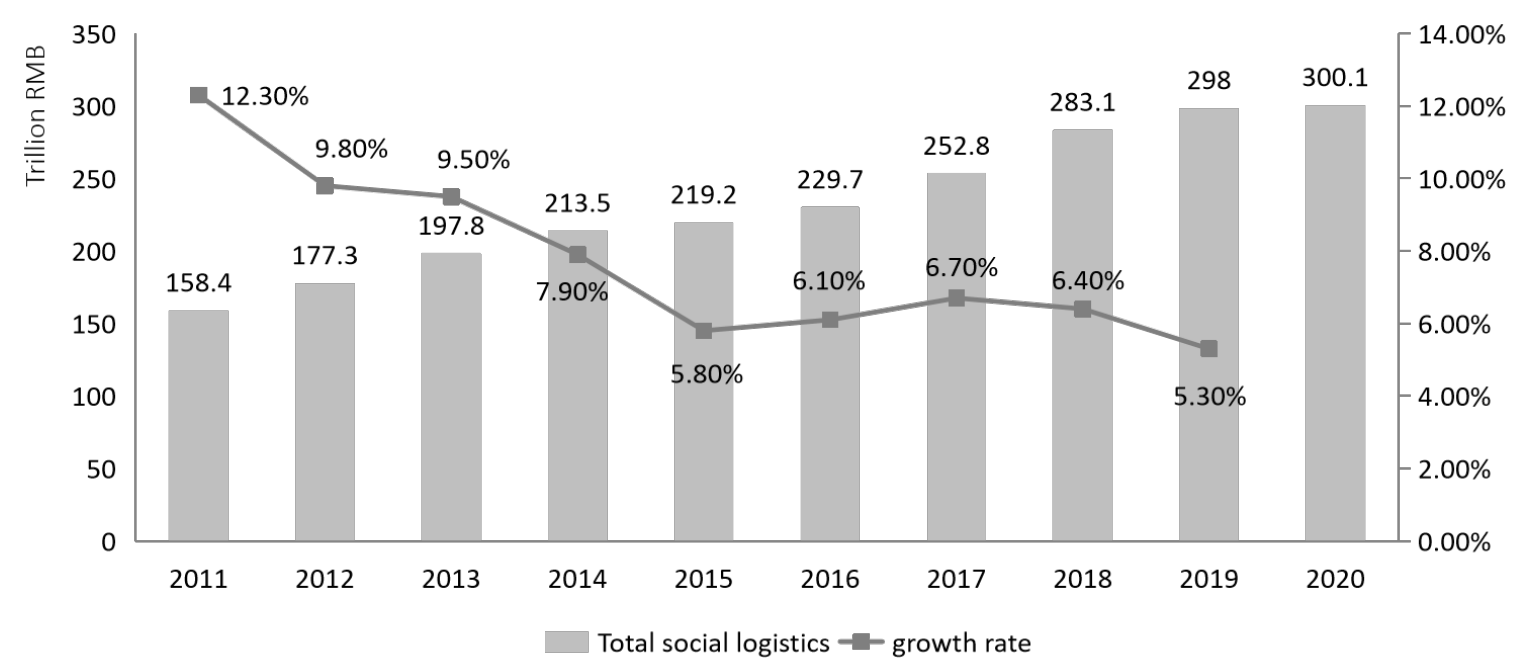

Figure 1. Trend chart of China's total social logistics from 2011 to 2020. Source: China Federation of logistics and purchasing.

Aiming at the relationship between modern logistics industry and regional economic development, $\mathrm{Na} \mathrm{L}$ (2018) analyzed the role of logistics industry in promoting regional economic development from four aspects: industrial structure, infrastructure, employment and investment, and analyzed the impact of regional economy on logistics industry from three aspects: development level, scale and structure. In fact, domestic and foreign scholars' research on China's logistics industry not only includes the coordination

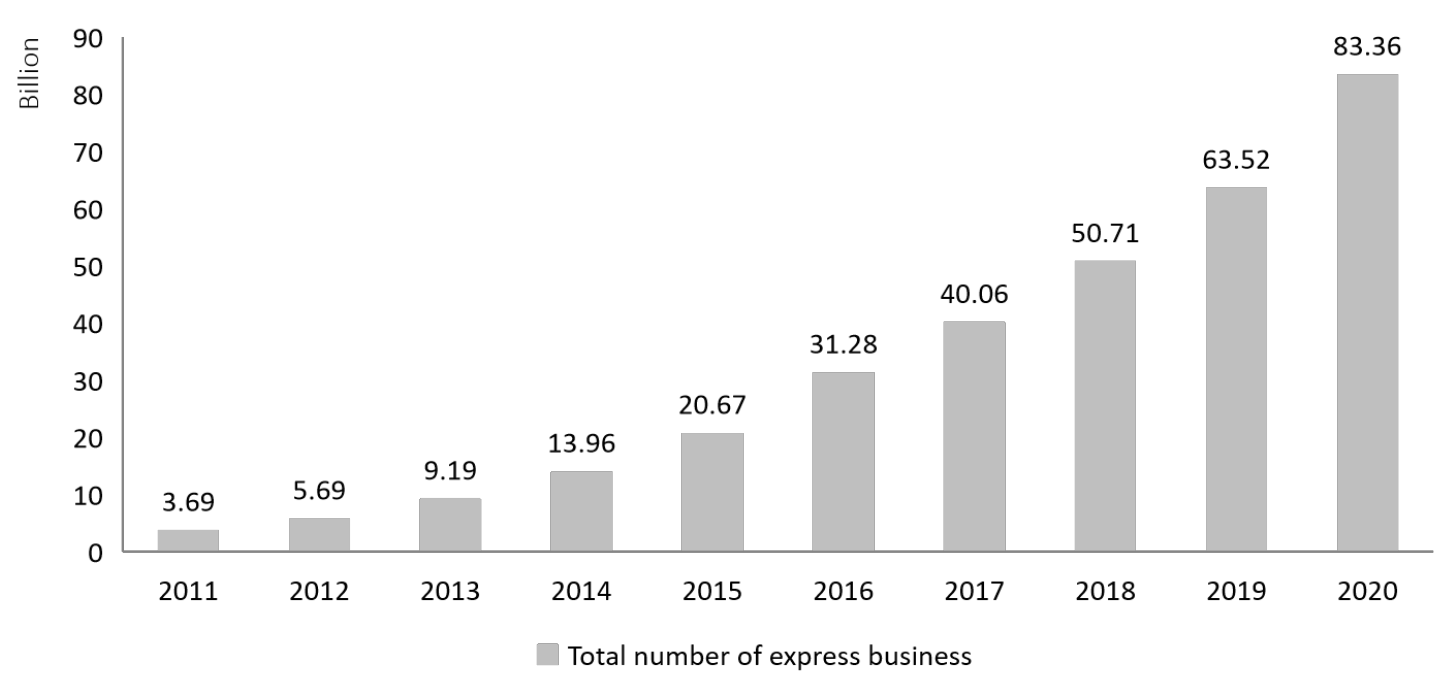

Figure 2. Changes in China's express business volume from 2011 to 2020. Source: State Post Bureau. 
relationship between the logistics industry and the regional economy and the interaction mechanism between logistics industry clusters and related industries, but also involves the planning and construction of a new generation of logistics industrial parks. This paper uses the methods of literature survey and empirical research to explore the planning model of China's new generation Logistics Industrial Park.

\section{Development of logistics industrial parks in China}

\subsection{Developing course}

The real logistics park in China started in 1999. The proposal of Shenzhen Pinghu Logistics Base is the beginning of China's logistics park construction. Between 1999 and 2000, some areas with high marketization and strong logistics demand began to plan logistics parks. This stage is called the introduction period. The period from 2001 to 2003 is the growth period of the development of logistics parks. The governments of more than 20 provinces and cities in China and more than 30 central cities have formulated regional logistics development plans and policies. From 2003 to 2004, the development of China's logistics parks entered a stage of adjustment in order to cope with the problems that emerged during the exploration process. Since 2004, the construction of China's logistics parks has gradually moved from blindly to scientific, systematic and standardized, and has entered a development period. The number of logistics parks has grown steadily. In 2018, the number of China's logistics parks has reached 1,638 . With the upgrading of consumption and technological innovation represented by artificial intelligence, big data and cloud computing, modern supply chain has become a new driving force for economic development. The new generation logistics industry has become an indispensable node between enterprises and consumers, virtual economy and real economy. The construction of the new

\begin{tabular}{lll}
\hline Periods & Brief introduction \\
\hline 1999-2000 & Introduction period & $\begin{array}{l}\text { The proposal of Shenzhen Pinghu logistics base in 1999 is the beginning of the } \\
\text { construction of China's logistics park. Some regions with high degree of } \\
\text { marketization and strong logistics demand began to plan logistics parks. }\end{array}$ \\
2001-2003 & Growth period & $\begin{array}{l}\text { The governments of more than } 20 \text { provinces and cities and more than } 30 \\
\text { central cities in China have formulated regional logistics development plans } \\
\text { and policies. }\end{array}$ \\
2003-2004 & Adjustment period & $\begin{array}{l}\text { There was blindness in the construction of some logistics parks, and the growth } \\
\text { rate of the number of logistics parks in China slowed down. } \\
\text { 2004-Present }\end{array}$ \\
\cline { 2 - 3 } & Development period & $\begin{array}{l}\text { The construction of China's logistics parks began to move from blindness to } \\
\text { scientization, systematization and standardization, and the number of logistics } \\
\text { parks increased steadily. }\end{array}$ \\
\hline
\end{tabular}

Table 1. Development of logistics parks in China. Source: Self-made.

generation Logistics Industrial Park is also in full swing (Table 1) .

\subsection{Planning characteristics}

In 2018, the business of China's logistics park has involved customs, industry and commerce, taxation, insurance, finance and other fields. The construction of a new generation of logistics park puts more emphasis on multiple linkages of the industrial chain, showing the following characteristics in terms of planning and site selection, spatial layout and investors:

A. Suburban site selection of the park under the background of market economy. Considering the suitability of space and the maximum utilization of resources, the location of the new generation logistics park has become the primary choice to realize the synchronous development of industry and city. The suburban area is a hub connecting cities and villages, which provides a strong site support for the logistics industry to improve service standards and reduce transportation costs. 
B. Network space layout under the promotion of functional linkage. The new generation of logistics parks no longer only assume the single social role of 'logistics'. The gradual enrichment of the logistics industry chain has broadened the functional attributes of logistics land. It is no longer limited to the allocation of logistics and distribution infrastructure, but more attention is paid to service optimization and upgrading and resource integration and sharing. Logistics parks have gradually shifted from single-point competition to network competition, presenting different levels of networked shared space layouts, and the benign interaction and linkage development between industries have further promoted industrial integration.

C. Diversified subject investment driven by 'big data'. The advent of the era of 'big data' and new technology provides opportunities for transformation and upgrading of the modern service industry. As the number of logistics parks increases year by year, investment entities are no longer limited to logistics companies, but also involve other areas of operation management and investment construction.

\subsection{Development trend}

New technologies, new models, and new business formats are affecting the development of China's new generation of logistics parks and promoting the transformation of China's logistics parks into smarter ones.

A. Transformation trend of logistics industry pattern. The logistics industry of China has developed into the era of borderless logistics and intelligent logistics after experiencing the early stage of physical distribution focusing only on warehousing and transportation and the intermediate stage of logistics services integrating some services. With the increasing logistics demand for high-end product, road logistics is at an advantage due to the small freight capacity and high flexibility. The comprehensive interoperability of information Internet and facilities Internet of things are complementary to the road logistics transport mode. The multi-way linkage of transport function, industry chain and information platform will form a "logisticst" model, which is a new logistics industry model to promote regional economic development.

B. Intensive trend of logistics spatial scale.The construction of new logistics industrial parks strengthens the mixed and composite degree of the park and emphasizes the intensive and efficient use of land.

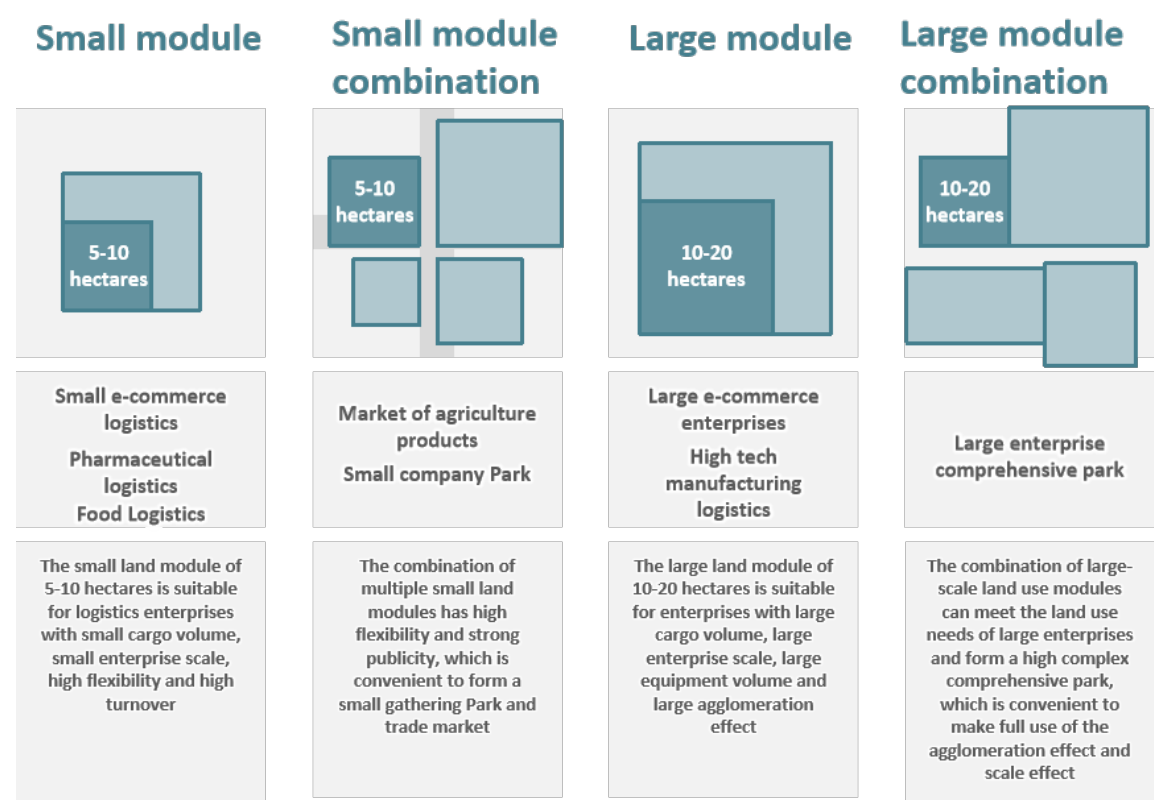

Figure 3. Elastic combination of different types of logistics land. Source: Self-made. 
The actual area covered by logistics parks in China is concentrated within 2,000 mu, and the construction scale is oriented by suitable, efficient and intensive scale. The area of road port logistics parks is generally around $0.7 \mathrm{~km}^{2}$ to $5 \mathrm{~km}^{2}$. The area of large-scale parks, such as the Jiaxing Logistics Park in the Yangtze River Delta Economic Zone, the Shenzhen Qianhai Logistics Park in the Pearl River Delta Economic Zone, and the Chongqing Banan Road Logistics Base in the southwest, is $6 \mathrm{~km}^{2}$ or more, but not more than $9 \mathrm{~km}^{2}$. In short, the modern emerging logistics parks based on roads is mostly "small and precise" and adopts the dominant approach of 'flexible and scattered' and 'multipoint layout' in different regions or cities. (Figure 3).

C. Integration trend of logistics platform forms. The logistics parks in China are entering the stage of digital transformation, and are mostly the integrated service platforms dominated by modern trade logistics that serve different regions based on cities, with high-end integration of production and life. It's necessary to make full use of basic functions, extended functions and information platform functions to combine logistics with the primary industry, in order to create green agricultural products trade logistics; combine logistics with the secondary industry to promote the standard logistics in the high-new manufacturing industry; combine logistics with the tertiary industry to facilitate the e-commerce logistics in the people service industry. Meanwhile, it is also required to consider the functions of ecological services, agricultural services and cultural tourism services to jointly create a 'logisticst' industrial system, promote the integrated development of multiple industries, and fully support the integrated development of logistics.

\section{Analysis of Typical Logistics Park-Baisi Logistics Group}

Baisi logistics group, a new generation of logistics industry space located in the suburbs of the city, is an important fulcrum for Hebi City, a city in Central China, to radiate Shanxi, Hebei, Shandong and Henan provinces and improve the regional service level. It has the conditions to undertake the functions of regional high-end industrial services and modern commercial logistics, and help improve the regional status of Hebi by relying on the Beijing-Guangzhou corridor.

\subsection{Development conditions}

In terms of traffic location, the logistics group is located within a 20-kilometer service circle of a 4C-level airport(Civil aviation standard - MH 5001-2006 <technical standard for civil airport flight area>), and is relatively close to the double high-speed rail lines of Hebi East Station and Huajun Station. It can be combined with the development of high-speed rail and airport to form 'air, rail, and public' multi-linked transportation, and it is possible to undertake the development of high-end business logistics, life business logistics, express logistics, e-commerce logistics and other multi-functional industries. In terms of natural resources, the Baisi Logistics Group is close to the city's country parks and has good ecological conditions, which can realize the integration and development of 'ecology, production, and living' spaces. At the same time, due to the numerous historical relics surrounding the logistics park, it can continue to continue the cultural characteristics of Chinese style and innovative fashion, and develop cultural leisure, innovative creativity, cultural commerce, high-end business logistics, high-end residence, headquarters office and other functions.

\subsection{Spatial planning}

The Baisi logistics group comprehensively considered the construction conditions and industrial demand on the basis of the current land use, and added $7 \mathrm{~km}^{2}$ of industrial land, with a total land scale of $11 \mathrm{~km}^{2}$. The actual service population is expected to be about 50,000-80,000. The Baisi logistics group presents an irregular shape in the overall space, with finger-like green corridors infiltrating it from the southeast, forming a spatially integrated development model of 'residential cluster + logistics park + township' of 
Yao, C.; Qin, X.;

Zuo, G.
Spatial Plan Research based on a new generation of suburban logistics industry in China

industry, city and landscape. The construction land area of the residential cluster is about $1.1 \mathrm{~km}^{2}$, which can meet the needs of about 10,000 to 20,000 residents. The construction land area of the commercial logistics area is about $7.6 \mathrm{~km}^{2}$, including medical logistics, bulk logistics, brand e-commerce, e-commerce science and innovation, intercity commerce and other functions. It can accommodate 3-5 leading logistics enterprises and more than 100 professional logistics and service supporting enterprises, and can meet the needs of about 10000-20000 residents. The construction land area of the market town comprehensive service area is $2.5 \mathrm{~km}^{2}$, which can meet the resettlement and life of about 30000-40000 local residents, and can also carry the functions of comprehensive services and characteristic culture and tourism.

In addition to the traditional business logistics functions, the logistics park extends upward to the functions of business finance, headquarters office, intelligent service, scientific and technological research and development, e-commerce maker incubation, brand incubation, vocational education and training, etc. Downward extension of functions such as smart logistics, processing industry and related industries. The planned commercial logistics area will form a functional ratio of $70 \%$ of the industrial part (including $30 \%-50 \%$ of warehousing and logistics) and $30 \%$ of the supporting part. The industry part includes functions such as warehousing and logistics, business transactions and derivative industries, and

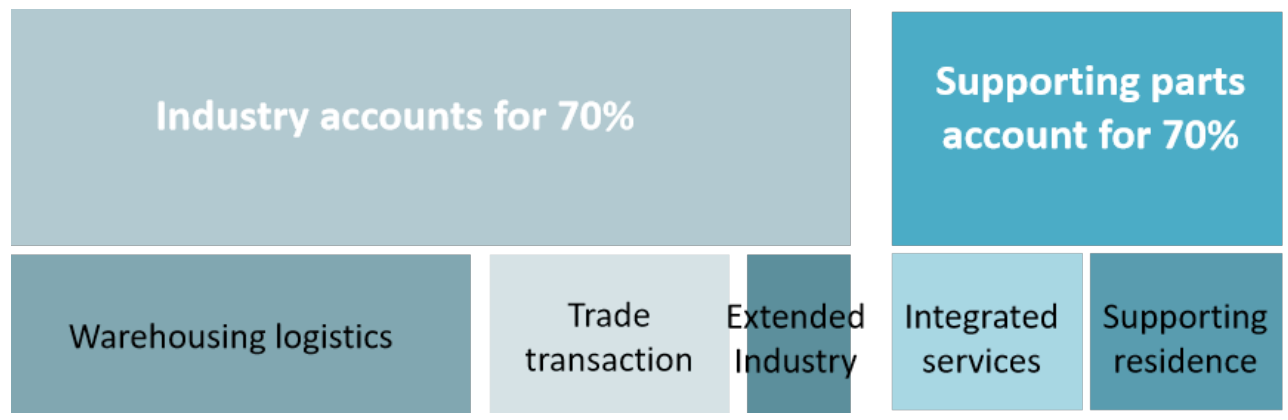

Figure 4. Classification and proportion of main functions. Source: Self-made.

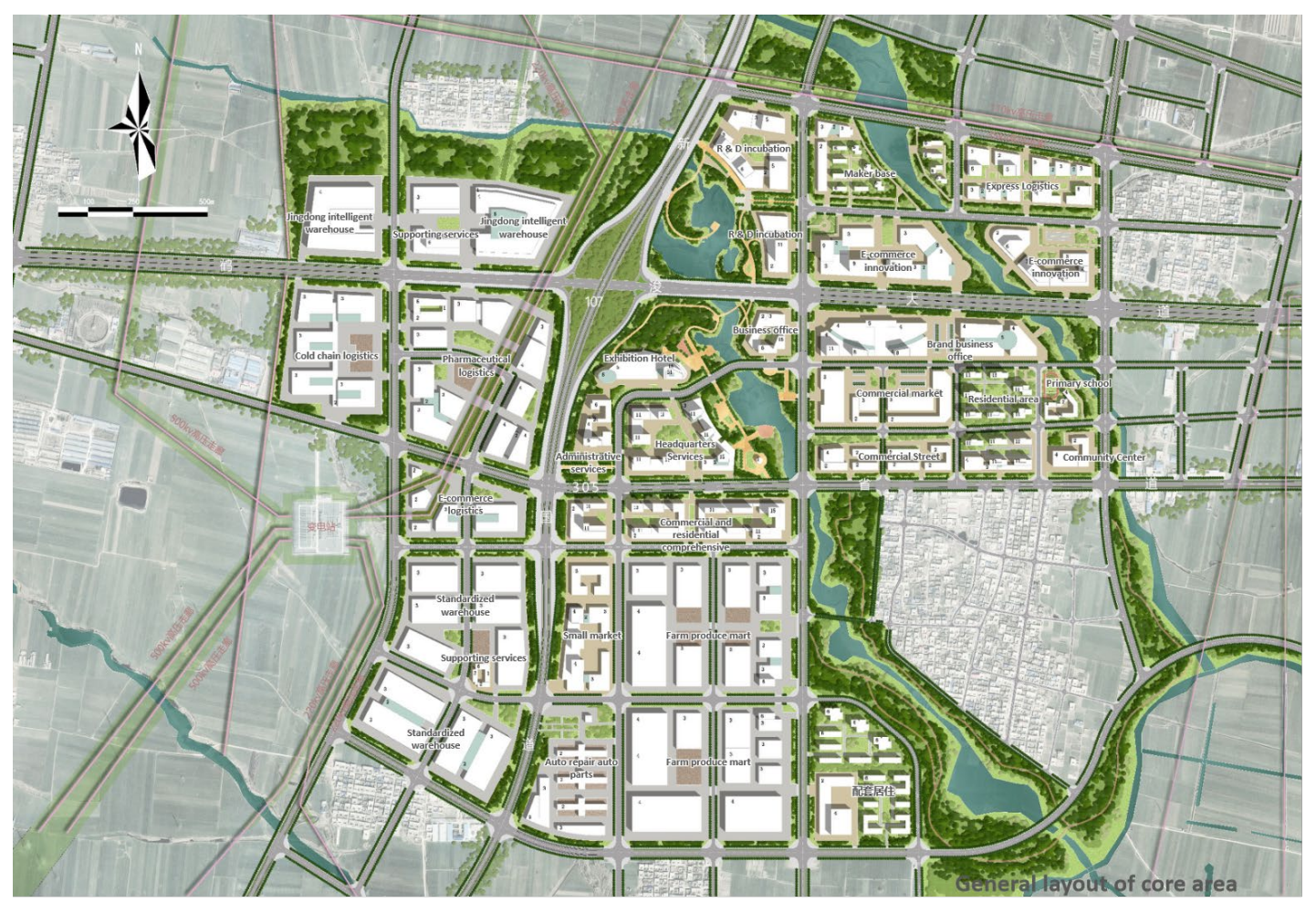

Figure 5. The overall layout of the core area of the Baisi logistics group. Source: Self-made. 
the supporting part includes functions such as commerce, training and residence (Figure 4,Figure 5) .

The plan emphasizes the spatial organization mode of the front store and the rear park of the logistics park. The two sides of the main transportation interface form functions such as commerce, research and development, and office. Several logistics units are arranged on the back of the service interface to fully activate the value of land use. The unit combinations of different sizes are formed through land division, including 0.1-0.4 $\mathrm{km}^{2}$ of units carrying e-commerce, scientific innovation and brand e-commerce, 1-1.5 $\mathrm{km}^{2}$ of units carrying bulk logistics, and about $0.4-0.8 \mathrm{~km}^{2}$ of units carrying intercity commerce and comprehensive services.

\section{Construction of Planning Mode for China's New Generation Logistics Industrial Park}

Combined with the construction characteristics of Baisi logistics group and meeting the requirements of regional and urban high-quality development in the new era, this paper discusses the planning mode of building a new generation of Logistics Industrial Park in China.

\subsection{Combination of spatial organization and changes in investment entities}

There are mainly five investment and operation cooperation modes in China's logistics industry parks: land use rights paid transfer mode, self-operation and bidding operations, 'investment-operationtransfer' mode, joint venture mode, and government-enterprise cooperation mode. Most of the new generation of logistics parks adopt a cooperative operation form led by the government and enterprises as the main body. The main body of investment in the logistics park is constantly changing with the upgrading of the logistics industry and the increase of logistics types. Considering its complex and diversified investors, the spatial organization of the new generation Logistics Industrial Park forecasts and elastically adjusts the scale of different types of logistics land to form block modules of different sizes, which can effectively deal with various uncertain factors in the development process on the premise of meeting the needs of industrial positioning.

\subsection{Combination of business format and Internet economic needs}

'Reducing costs and increasing efficiency' is the most urgent need of the logistics industry, and it is also the purpose of the transformation and upgrading of logistics enterprises' automation and information technology. The Internet economy has given birth to artificial intelligence technology, which has achieved a greater degree of 'cost reduction and efficiency increase'. Under its influence, the format composition of China's new generation Logistics Industrial Park is not only maintaining the traditional commercial logistics format, but also extending to both ends of the industrial chain. Upward is to extend to business finance, headquarters office, smart service, technology research and development, e-commerce maker incubation, brand incubation, vocational education and training; downward, to extend to smart logistics, processing industry, and related industries to undertake and refine business formats. With the wide application of emerging technologies and the continuous upgrading of user experience, new challenges will appear in the operation ideas and business models of the new generation Logistics Industrial Park. Combining the business form composition with the needs of the Internet economy can have a relatively broad development space on the premise of controlling the logistics cost of enterprises.

\subsection{Combination of supporting facilities and integrated development of industry and city}

Logistics park is a place for centralized organization and management of logistics nodes. Firstly, it has social functions such as promoting regional economic development and enhancing regional competitiveness. Secondly, it has basic business functions, including transportation, warehousing, packaging, loading and unloading, handling, circulation processing, distribution, information and 
consulting services. At the same time, the construction of office, financial, living, and comprehensive services supporting business functions is also indispensable. The construction of China's new-generation logistics industrial park has typical Chinese characteristics in terms of supporting facilities and valueadded services, that is, it is integrated with the development of industry and city. First, consider the integration of industry and countryside, improve the characteristic logistics industry chain and improve the quality of rural logistics industry by adding auxiliary service functions with rural characteristics; The second is the combination of industry and urban area. By coordinating the relationship between industrial functions and residential communities, integrating supporting facilities, promoting the balance between work and housing, and realizing the integration of 15 minute life circle and employment circle.

\subsection{Combination of landscape image shaping and 'Chinese dream'}

As a socialist country, China upholds the Marxist ecological economy thinking, combined with China's actual development situation, and regards the construction of ecological civilization as an important way to lead China's economic growth and realize the 'Chinese Dream'. The construction of China's newgeneration logistics industrial park has also clarified the direction of green development. Ecological maintenance is as important as economic growth. The new construction mode requires the park to shape the landscape on the basis of maintaining the ecological environment, reflect the Chinese style, strictly abide by the ecological bottom line, separate the functional areas with natural elements such as pastoral, green corridor and water system, create a characteristic layout integrating ecology and life, and realize the high fit between the physical industry and the ecological and cultural landscape. The logistics industry cluster 'surrounded by blue and green and integrated with culture and scenery' is the result of industrial division with Chinese characteristics, the basic direction of building a green and low-carbon circular development industrial system, and an important embodiment of the 'Chinese dream'.

\section{Conclusion and outlook}

After in-depth understanding of the development history, planning characteristics and development trends of China's logistics industrial parks, the importance of space utilization in the suburbs of Chinese cities has been affirmed. The analysis of the Baisi logistics group in Hebi City, Henan Province is helpful to explore the planning methods of logistics industrial parks under the background of the Internet economy and the requirements of regional high-quality development, and further build the basic planning model of China's new generation of logistics industrial parks. The planning of China's new-generation logistics industrial park requires the combination of spatial organization and changes in investment entities, business structure and Internet economic development, facilities and industrial-city integration and development, and landscape modeling and the 'Chinese Dream'. Therefore, this study will focus on the functional transformation and economic activation of the new generation Logistics Industrial Park, which provides a new method and new path for promoting urban-rural integration and realizing regional highquality development. However, in terms of specific planning strategy and detailed layout design, further discussion and thinking are needed.

\section{References}

Chen, Z. (2011) Research on the core competitiveness of science and technology enterprises. Beijing: China Science and Technology Press. (in Chinese)

Crooks, A., Montello, D., Bai, X., Rodrigue, J. and Bearman, N. (2013) 'Review: A Framework for Geodesign: Changing Geography by Design, Cognitive and Linguistic Aspects of Geographic Space: New Perspectives on Geographic Information Research, City Suburbs: Placing Suburbia in a Post Suburban World, Brands and Branding Geographies, Logistics Clusters: Delivery Value and Driving Growth, Studies in Applied 
Geography and Spatial Analysis: Addressing Real World Issues, Environment and Planning B: Planning and Design, 40(6), P1122-1130.

Ghelichi, Z. Gentili, M. and Mirchandani, P. (2021) 'Logistics for a fleet of drones for medical item delivery: A case study for Louisville, $\mathrm{KY}^{\prime}$, Computers \& Operations Research, 135, p105443.

Gong, X. and Jin, L. (2020) 'Research on efficiency evaluation and temporal and spatial differences of China's logistics industry under the background of cost reduction and efficiency increase', Business Economics Research, (14), p 100-103. (in Chinese)

Han, B., Wan, Y. and Duan, J. (2018) 'Decomposition of factor substitution elasticity of China's logistics industry', Statistics and decision making, 34(24), p 134-137. (in Chinese)

He, Y. (2016) 'Industrial Transfer under Synergy Development Analysis between Key Industries and Logistics Capability', Open Journal of Social Sciences, 4(1), p96-104.

Hosseini, M., Rameezdeen, R., Chileshe, N. and Lehmann, S., (2015) 'Reverse logistics in the construction industry. Waste management \& research', the journal of the International Solid Wastes and Public Cleansing Association, 33(6), p499-514.

Huang, S. (2013) 'Development of logistics park from prisoner's dilemma to cooperative game', China's circulation economy, 27(9), p 35-41. (in Chinese)

Li, N. (2018) 'Analysis of the relationship between modern logistics and regional economic development', Modern Marketing (late issue), (12), P 117.(in Chinese)

Li, Q. (2016) 'Research on the construction of management information platform of China ASEAN smart Logistics Park', Journal of Guangxi Economic Management Cadre College, 28(4), p 7-13. (in Chinese)

Liu, L. and Meng, Q. (2020) 'Study on efficiency evaluation and influencing factors of logistics industry in eastern China -- Based on panel data from 2008 to 2017', Journal of Hunan University of Technology, 34(2), p66-72. (in Chinese)

Li, W. (2008) Sustainable development and core competitiveness of cities. MA. Chengdu University of Technology. (in Chinese)

Mohapatra, S., Pani, A. and Sahu, P. (2021) 'Examining the Impacts of Logistics Sprawl on Freight Transportation in Indian Cities: Implications for Planning and Sustainable Development', Journal of Urban Planning and Development, 147(4), P04021050.

Poliak, M. and Varjan, P. (2015) 'The Possibility of Using Knowledge from Unconventional Financing of Suburban Bus Transport as an Innovative Tool for Cost Reduction in Logistics', Applied Mechanics and Materials, 803, P47-53.

Sakai, T., Kawamura, K. and Hyodo, T. (2015) 'Locational dynamics of logistics facilities: Evidence from Tokyo', Journal of Transport Geography, 46(46), p10-19.

Shao, G. and Wu, J. (2020) 'Research on the development path of China's intelligent logistics industry chain from the perspective of capital', Special zone economy, (4), p 118-121. (in Chinese)

Shi, Y., Li, H., Song, W. and Yan, J. (2013) 'Research on Separating Mode of Business and Logistics', Applied Mechanics and Materials, 397-400, p2651-2654.

Wang, Y. (2011) 'Research on Bazhou city positioning and Development Countermeasures of regional central city',Shanxi Architecture, (36), p 19-20. (in Chinese)

Wu, Z. (2007) Research on urban brand competitiveness based on the concept of sustainable development. MA. Chengdu University of Technology. (in Chinese) 
Yan, L. (2010) 'Research on logistics system planning of China's building ceramics industry base', Logistics technology, 29(15),p 8-9+19. (in Chinese)

Zhang, B. (2019) 'The development of Japanese logistics industry and Its Enlightenment to China's logistics industry', China logistics and procurement, (14), p 67-68. (in Chinese)

Zhao, J. (2007) Study on the core competitiveness of county economy -- Taking Qingzhen City as an example. MA . Guizhou University. (in Chinese)

Zhao, Q. (2005) Research on the core competitiveness of local colleges and universities in non central cities. MA. Northwest Normal University. (in Chinese)

Zheng, H. (2013) 'Research on the problems and Countermeasures of the construction of core competitiveness of small and medium-sized enterprises in China', Management scientist, (3), p 514-515. (in Chinese) 